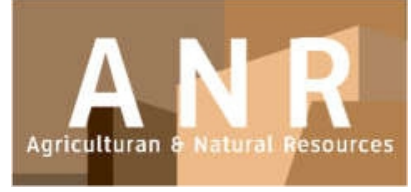

PAPER - OPEN ACCESS

\title{
Peran Subsektor Kehutanan Terhadap Pembangunan Ekonomi Kalimantan Tengah Era Reformasi
}

\author{
Author : Jumri dan Mayawati \\ DOI $\quad: 10.32734 /$ anr.v2i1.573 \\ Electronic ISSN : :2654-7023 \\ Print ISSN : :2654-7015
}

Volume 2 Issue 1-2019 TALENTA Conference Series: Agricultural and Natural Resources (ANR)

\section{(2) $(1)$}

This work is licensed under a Creative Commons Attribution-NoDerivatives 4.0 International License.

Published under licence by TALENTA Publisher, Universitas Sumatera Utara

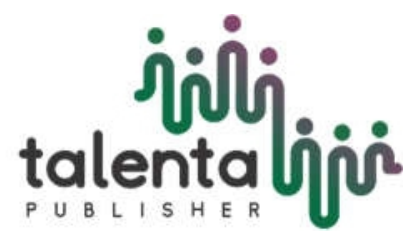




\title{
tolenthilh hion TALENTA Conference Series
}

Available online at https://talentaconfseries.usu.ac.id

\section{Peran Subsektor Kehutanan Terhadap Pembangunan Ekonomi Kalimantan Tengah Era Reformasi}

\author{
(The Role of Forestry Subsectors on Central Kalimantan Economic Development in the Reform Era)
}

\author{
Jumri dan Sari Mayawati*) \\ *) Fakultas Pertanian, Jurusan Kehutanan, Universitas Palangka Raya
}

Email: jumridulamin01@gmail.com,mayajumri@yahoo.co.id

\begin{abstract}
Abstrak
Hutan sebagai modal pembangunan nasional telah berperan penting dalam pembangunan ekonomi Indonesia. Sejak beberapa dekade khususnya tahun 1970-1990 hutan telah memberikan kontribusi terhadap perekonomian dan pada waktu itu semua orang berpikiran bahwa hutan adalah sumber penghidupan yang berasal dari anugrah Tuhan Yang Maha Esa dan merupakan lumbung kehidupan bagi umat manusia di permukaan bumi. Di era reformasi kontribusi subsektor kehutanan telah mengalami penurunan baik secara nasional maupun regional. Tujuan penelitian adalah menganalisis perkembangan nilai subsektor kehutanan terhadap pertumbuhan ekonomi propinsi Kalimantan Tengah era reformasi, melalui besaran nilai kontribusi yang dihasilkan oleh subsektor kehutanan terhadap besar nilai produk domestik regional brutto (PDRB). Metode penelitian yang digunakan adalah wawancara dan pengumpulan dokumentasi sebagai data penujang. Analisis data menggunakan metode trend simple exponential dengan metode sebagai berikut $\mathrm{Y}^{\prime}=\mathrm{ab}^{\mathrm{x}} ; \log \mathrm{Y}^{\prime}=\log \mathrm{a}+(\log \mathrm{b}) \mathrm{X}$. Jika $\sum \mathrm{X}=0 ; \log \mathrm{a}=\left(\sum \log \mathrm{Y}\right): \mathrm{n} \operatorname{dan} \log \mathrm{b}=\left\{\sum \mathrm{X}(\log \mathrm{Y})\right\}: \sum \mathrm{X}^{2} . \operatorname{Hasil}$ penelitian menunjukkan bahwa kontribusi yang dihasilkan dari subsektor kehutanan terhadap pertumbuhan ekonomi propinsi Kalimantan Tengah era reformasi khususnya terhadap nilai PDRB 1998-2010 cenderung mengalami penurunan sebesar -1,75\%, namun mulai tahun 2011-2017 mengalami kenaikkan secara fluktuatif dengan rata kenaikkan pertahun sebesar 0,06\%. Kontribusi subsektor kehutanan terhadap nilai produk domestik regional brutto Kalimantan Tengah pertahun mencapai 6,29\%.
\end{abstract}

Kata kunci: Kontribusi, Kehutanan Sub-sektor, Pembangunan

\begin{abstract}
Forests as a national development capital have played an important role in Indonesia's economic development. Since decades, especially in 1970-1990, the forest has contributed to the economy, and at that time everyone thought that forests were a source of livelihood that originated from the grace of God Almighty and was a barn of life for humanity on the surface of the earth. In the reform era, the contribution of the forestry subsector has decreased both nationally and regionally. In the reform era, the contribution of the forestry subsector has decreased both nationally and regionally. The study aimed to analyze the development of the forestry sub-sector value towards the economic growth of the Central Kalimantan province in the reform era, through the amount of the contribution generated by the forestry sub-sector to the value of the gross domestic product (GRDP). The research method used was interviews and collection of documentation as data of the assessor. Data analysis uses the trend simple exponential method with the following method $Y^{\prime}=a b x ; \log Y^{\prime}=\log a+(\log b) X$. If $\Sigma X=0 ; \log a=(\Sigma \log Y): n$ and $\log b=$ $\left\{\sum X(\log Y)\right\}: \Sigma X 2$. The results showed that the contribution generated from the forestry sub-sector to the economic growth of the province of Central Kalimantan in the reform era, especially towards the value of the 1998-2010 GRDP tended to decrease by $-1.75 \%$, but from 2011-2017 there was a fluctuating increase with an annual increase of 0.06\%.
\end{abstract}

Keywords: Contribution, Forestry Sub-sector, Development.

(C) 2019 The Authors. Published by TALENTA Publisher Universitas Sumatera Utara

Selection and peer-review under responsibility of Pertemuan Ilmiah Tahunan (PIT) dan Seminar Nasional Ke-4,

Komunitas Manajemen Hutan Indonesia (KOMHINDO)

p-ISSN: 2654-7015, e-ISSN: 2654-7023, DOI: 10.32734/anr.v2i1.573 


\section{Pendahuluan}

Hutan sebagai modal pembangunan nasional telah berperan penting dalam pembangunan ekonomi Indonesia. Sejak beberapa dekade khususnya tahun 1970-1990 hutan telah memberikan kontribusi terhadap perekonomian dan pada waktu itu semua orang berpikiran bahwa hutan adalah sumber penghidupan yang berasal dari anugrah Tuhan Yang Maha Esa dan merupakan lumbung kehidupan bagi umat manusia di permukaan bumi. Sejalan dengan pemikiran di atas dan didukung oleh hukum kehutanan Republik Indonesia No.41/1999[1], sumber daya hutan merupakan kumpulan tumbuhan kayu dan bukan kayu serta unsur lingkungan yang terdapat didalamnya merupakan atau kesatuan. Artinya bahwa hutan harus dikelola dengan sebaik-baiknya dan digunakan seoptimal mungkin untuk kepentingan masyarakat. Dengan kata lain bahwa semua sumber daya alam yang terdapat dibumi ini harus dikelola dengan baik dan dipergunakan sebesar-besarnya untuk kepentingan masyarakat Indonesia (UUD 1945, pasal 33). Indonesia memiliki sumber daya hutan yang mempunyai peran luar biasa, dan bersifat tidak terbatas dan dapat diperbarui dengan cara pananaman kembali terhadap tegakan hutan. Oleh karena itu diperlukan kearifan bagi pengguna kayu diantaranya melalui penghematan bagi penggunaan kayu dan disiplin dalam peman faatannya. Pengelolaan hutan Indonesia selama 32 tahun (1968s/d2000), telah terjadi pemborosan terhadap sumber daya hutan Indonesia meski dengan dalih devisa negara namun disisi lain juga meninggalkan suatu permasalahan baru bagi Indonesia yaitu bertambahnya luas lahan kritis pada kawasan hutan yang barang tentu memerlukan penanganan secara serius.

Sesuai data [2], menyataka bahwa jumlah lahan kritis yang ada mencapai 4.636.466,01 ha (kondisi kritis sebesar 4.309.398,91 ha dan sangat kritis mencapai 327.067,10 ha). Artinya hutan yang mengalami kondisi seperti ini perlu sesegera mungkin mendapatkan perhatian dari pihak pemerintah agar hutan tersebut dapat memberikan manfaat dalam kehidupan masyarakat umum, khususnya masyarakat di Kalimantan Tengah. Sedangkan Kalimantan Tengah dengan luas kawasan hutan mencapai 12,7 juta ha diharapkan mampu berkontribusi terhadap pembangunan ekonomi di Kalimantan Tengah disamping sebagai penyeimbang iklim dunia. Hutan sebagai paru-paru dunia sudah barang tentu hutan yang ada di Kalimantan Tengah berkontribusi terhadap ketersediaan oksigen dunia demi kehidupan manusia yang ada dipermukaan bumi. Batasan masalah sebagai okjek penelitian yang disajikan dalam tulisan ini adalah data kontribusi sub sektor kehutanan terhadap nilai produk domestik regional bruto provisi Kalimantan Tengah selama 20 tahun pasca reformasi. Berdasarkan uraian, permasalahan dan batasan masalah di atas, maka penting dilakukan peneliti ini tentang "Peran Subsektor Kehutanan Terhadap Pembangunan Ekonomi Kalimantan Tengah Era Reformasi”.

Tujuan Penelitian adalah menganalisis perkembangan subsektor kehutanan terhadap besar nilai produk domestik regional bruto Provinsi Kalimantan Tengah era Reformasi. Manfaat penelitian adalah memberikan masukan kepada pemerintah dalam rangka pembangunan kehutanan kedepan, agar subsektor hutan dari waktu ke waktu dapat bermanfaat bagi kehidupan manusia.

\section{Metodologi Penelitian}

Penelitian ini dilaksanakan di provinsi Kalimantan selama 1 (satu) bulan yaitu dibulan April 2018. Metodologi penelitian dilakukan dengan cara wawancara dengan pihak Dinas Kehutanan dan Badan Pusat Statistik Provinsi Kalimantan Tengah, dan pengumpulan dokumentasi (data penunjang). Data pendukung penelitian diperoleh dari BPS dan Dinas Kehutanan Provinsi Kalimantan Tengah selama 20 tahun (time series)[3]. Analisis data menggunakan metode trend simple exponential [5] dengan model sebagai berikut: $Y^{\prime}=a^{x}, \log Y^{\prime}=\log a+(\log b) x . J i k a$ jumlah $x$ $=0, \log \mathrm{a}=($ jumlah $\log \mathrm{Y}): \mathrm{n} \operatorname{dan} \log \mathrm{b}=\{$ jumlah $\mathrm{x}(\log \mathrm{Y})\}:$ Jumlah $\mathrm{x}^{2}$.

\section{Hasil Dan Pembahasan}

Hasil analisis peran subsektor kehutanan terhadap pembangunan ekonomi Kalimantan Tengah era reformasi dilakukan dengan menggunakan metode trend simple exponential [5] di atas, disampaikan padab hasil perhitungan selanjutnya (table 1)

kontribusi subsektor kehutanan terhadap pembangunan ekonomi Kalimantan Tengah khususnya terhadap total nilai produk domestik regional bruto (PDRB) cendrung mengalami penurunan secara siknifikan dari tahun ketahun (1998-2017) dengan rata-rata kontribusi pertahun mencapai 6,29\% dengan diikuti pertumbuhan pertahun mencapai 10,92. Lebih jauh kalau dilihat sejak tahun 1998-2010 (Tabel.1) kontribusi yang dihasil dari subsektor ini terhadap 
nilai PDRB cendrung mengalami penurunan pertahun sebesar -1,75\%, namun mulai tahun 2011-2017 mengalami kenaikan secara fluktuatif dengan rata-rata kenaikkan pertahun sebesar 0,06\%. Artinya, bahwa subsektor kehutanan di era reformasi (1998-2010) sangat dipengaruh oleh berbagai faktor antara lain mata uang Indonesia melemah (rupiah) jika di bandingkan dengan USD Amerika sehingga berakibat ambruk dan bangkrutnya berbagai perusahaan maupun industri dalam negeri. Dalam kondisi ini subsektor kehutanan sangat terpuruk dengan terjadinya krisis ekonomi tersebut yang pada akhirnya berdampak negatif terhadap nilai perolehan yang bersumber dari kayu dan hasil hutan bukan kayu. Pada sisi lain adanya kebijakan pemerintah dalam hal perubahan status kawasan hutan menjadi kawasan perkebunan kelapa sawit, terjadinya praktek illegal loggin.

Tabel 1. Hasil perhitungani metode trend simple exponential terhadap peran subsektor kehutanan terhadap pembangunan ekonomi Kalimantan Tengah era reformasi 1998-2017 (Rp. Milyar)

\begin{tabular}{|c|c|c|c|c|c|c|c|}
\hline \multirow[b]{2}{*}{ Thn. } & \multirow{2}{*}{$\begin{array}{l}\text { subsektor } \\
\text { kehutanan }\end{array}$} & \multirow{2}{*}{$\begin{array}{l}\text { terhdp } \\
\text { PDRB }(\%)\end{array}$} & \multirow{2}{*}{$\begin{array}{l}\text { Pertumbuhan } \\
(\%)\end{array}$} & \multirow{2}{*}{$\begin{array}{c}\text { sektor } \\
\text { Pertanian }\end{array}$} & \multirow{2}{*}{$\begin{array}{c}\text { PDRB } \\
\text { Kalimantan } \\
\text { Tengah } \\
\end{array}$} & \multicolumn{2}{|c|}{ Trend $(\%)$} \\
\hline & & & & & & MTSE & PE \\
\hline 1998 & $2.065,3$ & 23,99 & - & $3.903,5$ & $8.609,7$ & 16,39 & $-6,92$ \\
\hline 1999 & $1.994,5$ & 20,88 & $-12,96$ & $4.426,2$ & $9.554,3$ & 14,18 & 0,98 \\
\hline 2000 & $1.572,6$ & 14,32 & $-31,42$ & $4.732,4$ & $10.980,5$ & 12,27 & 1,50 \\
\hline 2001 & $1.515,3$ & 12,30 & $-14,11$ & $5.129,1$ & $12.316,8$ & 10,61 & 2,95 \\
\hline 2002 & $1.519,3$ & 10,82 & $-12,03$ & $6.065,8$ & $14.047,8$ & 9,18 & 5,30 \\
\hline 2003 & $1.285,3$ & 8,24 & $-23,84$ & $6.769,3$ & $15.599,2$ & 7,94 & 4,91 \\
\hline 2004 & $1.191,1$ & 6,55 & $-20,51$ & $7.583,6$ & $18.183,5$ & 6,87 & 5,56 \\
\hline 2005 & 983,6 & 4,69 & $-28,40$ & $7.251,9$ & $20.983,2$ & 5,94 & 5,90 \\
\hline 2006 & 951,6 & 3,89 & $-17,06$ & $8.637,2$ & $24.480,0$ & 5,14 & 5,84 \\
\hline 2007 & 830,2 & 2,97 & $-23,65$ & $9.292,7$ & $27.932,0$ & 4,45 & 6,06 \\
\hline 2008 & 790,9 & 2,41 & $-18,86$ & $9.664,2$ & $32.760,2$ & 3,33 & 6,17 \\
\hline 2009 & 724,8 & 1,95 & $-19,09$ & $10.463,6$ & $37.114,2$ & 2,88 & 5,57 \\
\hline 2010 & $1.127,6$ & 1,20 & $-38,46$ & $13.935,4$ & $56.531,0$ & 2,49 & 6,50 \\
\hline 2011 & $1.147,0$ & 1,74 & 45 & $15.639,3$ & $65.871,4$ & 2,15 & 7,01 \\
\hline 2012 & $1.156,2$ & 1,58 & $-9,20$ & $16.953,1$ & $73.425,4$ & 1,86 & 6,87 \\
\hline 2013 & $1.233,7$ & 1,51 & $-4,43$ & $18.568,9$ & $81.956,9$ & 1,61 & 7,37 \\
\hline 2014 & $1.425,0$ & 1,59 & 5,30 & $21.181,4$ & $89.889,9$ & 1,39 & 6,21 \\
\hline 2015 & $1.739,8$ & 1,74 & 9,43 & $23.047,5$ & $100.063,5$ & 1,21 & 7,01 \\
\hline 2016 & $1.867,8$ & 1,67 & $-4,02$ & $24.665,4$ & $112.139,5$ & 1,04 & 6,36 \\
\hline 2017 & $1.978,0$ & 1,67 & 0 & $26.121,3$ & $126.176,1$ & 1,11 & 6,74 \\
\hline Jumlah & $27.099,6$ & 125,71 & $-218,31$ & $244.031,8$ & $938.615,10$ & 112,04 & 97,89 \\
\hline Rata-rata & $1.354,98$ & 6,29 & $-10,92$ & $12.201,59$ & $46.930,76$ & 5,60 & 4,90 \\
\hline
\end{tabular}

Keterangan:

$\mathrm{PE}=$ Pertumbuhan ekonomi

MTSE = Metode Trend Simple Exponential

Tahun 1998-2000 untuk tahun dasar 1993, tahun 2001-2010 untuk tahun dasar 2000 dan tahun 2011-2017 untuk tahun dasar 2010.

Lebih lanjut [6], menyatakan bahwa log berasal tebangan liar yang terjadi cukup besar bila dibandingkan dengan hasil tebangan yang syah (berijin) atau hampir tiga kali lipat dari sumber-sumber kayu legal. Kondisi ini menyebabkan

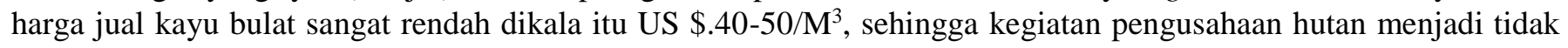
layak secara ekonomi. Nilai kayu/log yang hilang yang disebabkan praktek penebangan tanpa ijin/ tidak resmi di Indonesia sebesar Rp. 2,5 trilyun per tahun sumber lain menyatakan 101,73 juta hektar hutan Indonesia rusak (59,62 juta hektar terdapat didalam Kawasan hutan, 42,11 juta hektar diluar Kawasan hutan) [7]. Lebih lanjut (Tabel 1) di atas, khusus tahun 2011-2017 subsektor kehutanan sudah mulai kelihatan mengalami kenaikan secara fluktuatif dengan rata-rata kenaikkan pertahun sebesar $0,06 \%$, artinya subsektor kehutanan mulai bangkit kembali memberikan kontribusi terhadap pembangunan di Kalimantan Tengah tanpa mengabaikan sektor-sektor lainnya sebagai penggerak ekonomi di Kalimantan tengah. Dalam kondisi ini subsektor kehutanan perlu dipertimbangkan tentang besaran dana reboasasi per meter kubik kayu bulat diterima oleh negara selama ini, kalau memungkinkan pemerintah perlu mempertimbangkan nilai perolehan dari hutan berdasarkan perhitungan rente ekonomi kayu terhadap hasil produksi kayu bulat. Dalam rente ekonomi kayu di sini banyak hal yang menguntungkan pihak pemerintah, hasil penelitian 
menunjukkan bahwa penerimaan pemerintah lebih besar berdasarkan perhitungan rente ekonomi kayu dibandingkan dengan perhitungan DR dan PSDH [8].

Subsektor kehutanan merupakan salah satu subsektor dari sektor pertanian secara umum, oleh sebab itu subsektor kehutanan tidak dapat dipisahkan dari sektor pertanian. Hal ini dibuktikan bahwa kontribusi yang dihasilkan oleh subsektor kehutanan sangat berpengaruh terhadap jumlah sektor pertanian yang dihasilkan. Hasil penelitian ini menunjukkan bahwa kontribusi yang dihasilkan dari subsektor kehutanan terhadap sektor pertanian rata-rata pertahun mencapai Rp. 1.354,98 milyar $(11,11 \%$ ) dari rata-rata perolehan pertahun sektor pertanian secara umum (Rp.12.201,59 milyar). Sektor pertanian merupakan salah satu sektor andalan di Kalimantan Tengah dalam menunjang pertumbuhan ekonomi regional Kalimantan Tengah, terbukti sektor ini rata-rata pertahun berkontribusi terhadap pembangunan ekonomi Kalimantan Tengah mencapai Rp.12.201,59 milyar (26\%) dari rata-rata perolehan nilai produk domestik regional bruto Kalimantan Tengah sebesar Rp.46.930,76 milyar. Artinya sektor pertanian dimana di dalam sektor ini terdapat subsektor kehutanan, mempunyai peran penting terhadap pertumbuhan ekonomi di Kalimantan Tengah selain sektor-sektor lainnya. Pertumbuhan ekonomi yang tinggi merupakan impian semua orang, karena pertumbuhan ekonomi yang tinggi menunjukkan bahwa masyarakat memiliki daya beli yang baik terhadap kebutuhan ekonomi rumah tangga, kesempatan kerja banyak dan kesempatan berusaha dimana pada akhirnya masyarakat mencapai kesejahteraan. Di Kalimantan Tengah pertumbuhan ekonomi di era reformasi tahun 1998-2017 rata-rata pertahun 4,90\%, artinya pertumbuhan ekonomi seperti ini perlu dipacu agar menjadi lebih tinggi (6-7\%). Untuk mencapai pertumbuhan ekonomi dimaksud, maka semua sektor penggerak ekonomi perlu mendapat perhatian lebih dari pihak pemerintah, iklim investasi yang sejuk dan kepastian hukum terhadap kejahatan pelaku ekonomi.

Kawasan hutan Kalimantan Tengah cukup luas dan mampu memberikan kesejahteraan pada masyarakat bila dikelola dengan baik dan benar. Artinya semua sumber kehidupan masyarakat seyogyanya dapat dipenuhi dari hutan itu sendiri, karena hutan merupakan lumbung kehidupan dan paru-paru dunia. Hutan memiliki jasa lingkungan yang sangat diperlukan oleh manusian diatas bumi tentu keberadaannya perlu dipertahankan. Secara rinci keberadaan hutan Kalimantan Tengah di sajikan pada Tabel 2.

Tabel 2. Kondisi kawasan hutan Kalimantan Tengah berdasarkan SK.529/2012

\begin{tabular}{lcc}
\hline Uraian & Luas (ha) & Persentase \\
\hline Kawasan konservasi & 1.630 .828 & 10,57 \\
Hutan Lindung & 1.346 .066 & 8,73 \\
Hutan produksi terbatas & 3.317 .461 & 21,51 \\
Hutan produksi & 3.881 .817 & 25,16 \\
Hutan produksi konversi & 2.543 .535 & 16,49 \\
Areal penggunaan lain & 2.706 .293 & 17,54 \\
Jumlah & 15.426 .000 & 100,00 \\
\hline
\end{tabular}

Sumber: Dinas Kehutanan Propinsi Kalimantan Tengah, 2018.

Tabel 2 di atas menunjukkan bahwa hutan Kalimantan Tengah bila dikelola dengan baik sesuai prinsip pengelolaan berkelanjutan, tentu sangat menjanjikan bagi kehidupan masyarakat di Kalimantan Tengah secara khusus dan umumnya masyarakat Indonesia. Optimalisasi terhadap sumber daya hutan perlu dilakukan bukan saja terhadap hasil hutan berupa kayu melainkan terhadap hasil hutan non kayu perlu ditingkatkan serta jasa lingkungan hutan itu sendiri. [8] menunjukkan bahwa nilai jasa lingkungan hutan sangat besar misalnya nilai udara atau oksigen yang dihasilkan dari hutan dapat mencapai Rp.167.282.688/ha luas hutan (RP.717.642.731.520 : $4.290 \mathrm{Ha}$ ).

[2], menyatakan bahwa produksi kayu bulat di Kalimantan Tengah tahun 2013-2018 mencapai 10.759.203,70 M $^{3}$ atau rata-rata pertahun 1.793.200,62 $\mathrm{M}^{3}$. Data produksi tersebut dihasilkan dari pemegang IUPHHK-HA sebanyak 51 unit yang beroperasi di Kalimantan tengah. Dengan asumsi potensi hutan produksi di Kalimantan Tengah adalah 50 $\mathrm{M}^{3}$ perhektar, maka setiap tahun hutan yang di tebanga mencapai seluas 35.864 ha untuk 51 pemegang IUPHHK-HA atau untuk 1 pemegang IUPHHK-HA dengan luas tebangan 703,22 ha dan jumlah produksi kayu bulat 35.160,80 $\mathrm{M}^{3}$. Artinya bahwa hutan di Kalimantan Tengah masih signifikan untuk memproduksi kayu di Indonesia, meskipun hutan yang ada telah mengalami pengurangan luas yang disebabkan berkembangnya sektor ekonomi lainnya. Untuk menunjang keberlangsungan hutan di Kalimantan Tengah, usaha di bidang hutan tanaman industri (HTI) yang ada berjumlah 28 unit perlu dibina secara kontinyu karena HTI merupakan salah satu sebagai penghasil kayu untuk 
keperluan industri kehutanan dan berkontribusi terhadap pembangunan ekonomi di Kalimantan Tengah.

\section{Kesimpulan}

Untuk menjawab pertanyaan tentang perkembangan subsektor kehutanan terhadap pembangunan ekonomi diprovinsi Kalimantan Tengah era reformasi, hasil penelitian menunjukkan bahwa kontribusi yang dihasilkan dari subsektor kehutanan terhadap pertumbuhan ekonomi provinsi Kalimantan Tengah era reformasi khususnya terhadap nilai PDRB 1998-2010 cendrung mengalami penurunan pertahun sebesar -1,75\%, namun mulai tahun 2011-2017 mengalami kenaikan secara fluktuatif dengan rata kenaikkan pertahun sebesar $0,06 \%$. Secara umum bahwa kontribusi subsektor kehutanan terhadap nilai produk domestik regional bruto Kalimantan Tengah pertahun mencapai 6,29\%.

Saran peneliti terhadap pemerintah daerah provinsi Kalimantan Tengah adalah untuk lahan kritis yang terdapat di Kalimantan Tengah perlu di hutan kembali dengan cara program HTI Transmigrasi. Tujuannya adalah disamping mengurangi kepadatan penduduk yang ada di pulau jawa, lahan kritis yang ada dapat membentuk hutan kembali sehingga hutan lestari dan masyarakat mendapatkan hidup layak dan sejahtera. Pada sisi lain perlu dilakukan optimalisasi terhadap hasil sumber daya hutan yang ada danpeningkatan jasa lingkungan agar memperoleh nilai tambah dari hutan itu sendiri.

\section{Ucapan Terima Kasih}

Ucapan terimakasi ini disampaikan kepada yang terhormat Bapak pimpinan UPR, Bapak Dekan Fakultas Pertanian Universitas Palangka Raya, Ibu Ketua Jurusan Kehutanan Fakultas Pertanian Universitas Palangka Raya, Bapak Ketua KOMHINDO, Bapak/Ibu Panitia Seminar KOMHINDO III dan Bapak/Ibu Dosen sejawat Jurusan Kehutanan Fakultas Pertanian Universitas Palangka Raya.

\section{Referensi}

[1] Undang-undang Republik Indonesia, "No.41 Tahun 1999, Tanggal 30 September 1999, Tentang Kehutanan. Sekretariat Negara Republik Indonesia”. Jakarta, 1999

[2] Dinas Kehutanan Kalimanatan Tengah, "Laporan Bidang Perencanaan Hutan, Dinas Kehutanan Provinsi Kalimantan Tengah”, 2018.

[3] Badan Pusat Statistik, "Produk Domestik Regional Bruto Kalimantan Tengah" BPS, 2000-2017.

[4] Badan Pusat Statistik, "Kalimantan Tengah Dalam Angka”.BPS, 2017.

[5] Jumri, "Peranan Subsektor Kehutanan Terhadap Perekonomian Kalimantan Tengah Khususnya Produk Domestik Regional Bruto, Kesempatan Kerja Dan Ekspor” (Thesis Pasca Sarjana Unlam, Tidak Dipublikasikan). Banjarbaru. , 2006.“

[6] Asosiasi Pengusaha Hutan Indonesia (APHI), "Sumbangan Pemikiran APHI Kepada Bangsa : Konsep Mewujudkan Kembali Kebangkitan Sektor Kehutanan Dalam Pembangunan Nasional Kedepan”. Asosiasi Pengusaha Hutan Indonesia. Jakarta, 2004.

[7] Hidayati,R. et al., "Pemberantasan Illegal Logging Dan Penyeludupan Kayu Menuju Kelestarian Hutan Dan Peningkatan Kinerja Sektor Kehutanan". Banten, 2006.

[8] Jumri,, "The Optimization of Forest Resources Result Towards gross Regional Domestic Product (A Case Study in West Kotawaring in Regency, Central Kalimantan Province).” Academic Research International Vol. 6(4) July 2015, 2015 